form a connecting link between them all." The journal is intended for students as well as for past pupils of the hospital, and the objects of the new venture comprise the record of events of interest in connexion with the hospital and school, together with lectures, addresses, and clinical notes. The first number contains an excellent reproduction of a photograph of the late Mr. J. Whitaker Hulke, F.R.S., and among the literary matter we find a clinical lecture on Two Cases of Stone in the Bladder by Mr. Henry Morris, F.R.C.S. Eng., and a note on the Condition of the Kneejerks in Fracture-Dislocation of the Spine by Dr. Campbell Thomson. We congratulate the editor on the "get up" of the first number and wish the new venture every success.

St. Mary's Hospital Gavette. The first number of Vol. III. is embellished with a portrait of Surgeon-Lieutenant-Colonel A. T. Norton, V.D., whose career is also briefly sketched. Surgeon-Lieutenant-Colonel Norton, who is the popular commander of the Volunteer Medical Staff Corps (London companies), is also an old pupil and late member of the staff of St. Mary's Hospital, and has just been elected consulting surgeon to that institution. Among the Editor's Notes we observe an announcement that a new post of medical officer for the selection of out-patients bas been constituted. "The holder of this office, who must be a Member of the Royal College of Physicians, will attend the out-patient department daily and see all the new medical out-patients, and select each day not more than twenty-five cases of the greatest severity and transfer them to the physician to the outpatients, himself dealing with the remainder according to prescribed directions." By this arrangement it is hoped that benefit will ascrue both to patients and students. Would it not be possible for the new medical officer while making his selestion of suitable cases from a medical point of view to give an eye to each case with regard to the worthiness on the part of the patients to receive free treatment?

Knowledge.-This month the contribution to the series of articles on the Science of the Queen's Reign is from the pen of Miss Agnes M. Clerke, and deals briefly and in a popular way with the progress of astronomical research during the past sixty years. Under the heading A Pantheon of Science Mr. John Mills gives a summary of the history of the Royal Institution. It is some 100 years ago since that temple of science was first conceived by Benjamin Thomson, and the recent opening of the Davy-Faraday Laboratory, besides marking an epoch in the history of applied science in this country, forms a fitting memorial of the centenary of the Royal Institution of Great Britain.

The Cornhill Magazine.-There is a certain class of patients who are never satisfied unless their medical adviser "gives them something." To physicians who deal with such we recommend a perusal of an article by $\mathbf{E}$. H. Parker upon Diet and Medicine in China. Imagine the effect upon a nervous patient of seeing "toads' eyebrows" in a prescription. E. T. Murray Smith has an interesting article upon Two Centuries of National Monuments in Westminster Abbey. The eighteenth century, although it produced furniture, jewellery, miniatures, fabrics, porcelain, plate, bindings, and music all of the highest quality, was sunk in the lowest depths as regards anything ecclesiastical. Hence the paganism and hideousness of the monuments of the time. And the epitaphs! Here is a portion of one upon Admiral Vernon:

" Dying he bid Britannia's thunder roar,

And spain still felt bim when he breathed no more."

This is as good as-

$$
\begin{aligned}
& \text { "Fancy six hundred gentlemen at least, } \\
& \text { And each man mounted on a capering beast." }
\end{aligned}
$$

Some nineteenth century memorials are not in the highest art, witness the Stephenson window with the mud-dredger, but they are not so pretentious as their predecessors.

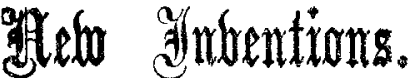

NEW TREPHINE,

ON several occasions on which I have had to trephine for compound depressed fracture of the skull it has cccurred to me that it would be an advantage to have an instrument without the central pirot pin and one which conld, therefore, completely encircle the depressed bone. With the old instrument, the pin having to be placed upon the edge of the underpressed part of the skull, obviously necessitates having to remove an unnecessarily large portion of sound bone and

Fig. 1.

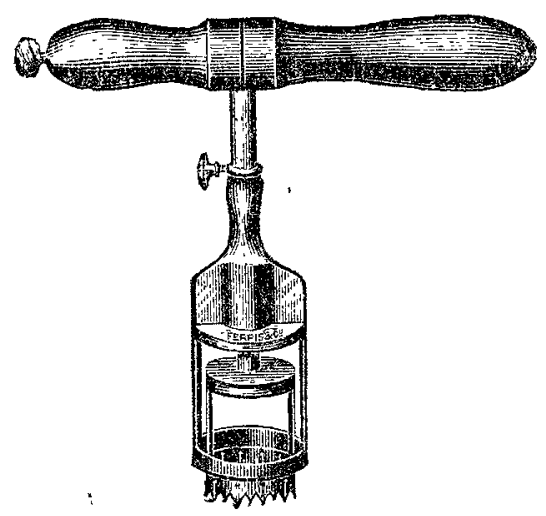

often the trephine cannot completely cover the fracture. Messrs. Ferris and Co. of Bristol at my suggestion have made an instrument which consists of a circular guard with three projecting points surrounding the saw edge, so as to get a purchase on the sound bone until a sufficiently deep groove has been cut. The guard can be held with the left hand while the right hand rotates the saw, and the guard can be made adjustable so as to regulate the depth of the saw cut. Trephines of various sizes can be adjusted to the same

FIG. 2

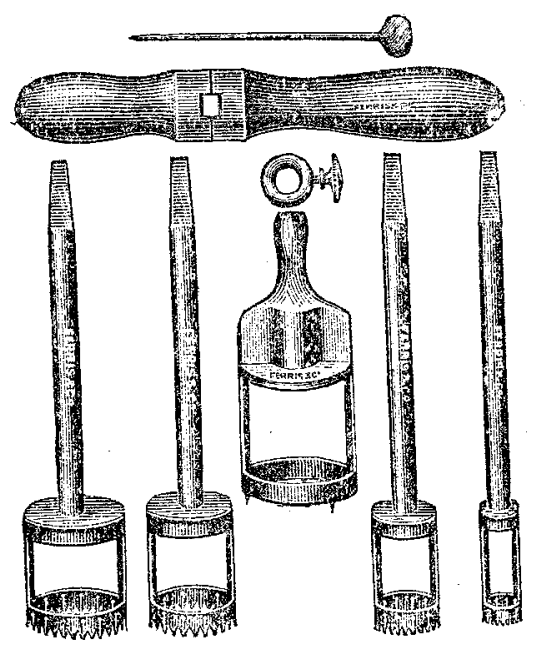

handle and only one guard is required. This instrument not only meets the particular object I had in view, but has also other advantages over the old-pattern trephine. The blade being open, it is light and the operator can see what he is doing. The stop collar on the stem regulates the depth of the saw cut. The whole instrument can be taken apart for cleansing and sterilising without any trouble.

WALTer Falla, M.R.C.S. Eng., L.R.C.P. Lond., Surgeon to the Jersey General Hospital.

\section{A THROAT IRRIGATOR.}

I wisH to call attention to a simple and effective throat irrigator which has been manufactured by Messrs. Maw, Son, and Thompson from a design of Miss S. Copeman, a district nurse. The fluid to be used is contained in a pear-shaped india-rubber ball of three or four ounces capacity, to which is screwed a metallic tube about five inches long, curved at right angles in the middle. This tube is about the size of a 